\title{
Whole-body regeneration in the colonial tunicate Botrylloides leachii
}

Simon Blanchoud ${ }^{1 *}$, Buki Rinkevich² \& Megan J. Wilson ${ }^{3}$

${ }^{1}$ Department of Biology, University of Fribourg, ch. du Musée 10, 1700 Fribourg, Switzerland

${ }^{2}$ Israel Oceanographic and Limnological Research, National Institute of Oceanography, Tel Shikmona, P.O. Box 8030, Haifa 31080, Israel

${ }^{3}$ Department of Anatomy, School of Biomedical Sciences, University of Otago, P.O. Box 56, Dunedin 9054, New Zealand

*corresponding author: simon.blanchoud@unifr.ch, +41 263008803

Keywords: whole-body regeneration, Botrylloides leachii, chordate, tunicate, ascidian

DOI: 10.1007/978-3-319-92486-1_16 


\section{Abstract}

The colonial marine invertebrate Botrylloides leachii belongs to the Tunicata subphylum, the closest invertebrate relatives to the vertebrate group, and the only known class of chordates that can undergo whole-body regeneration (WBR). This dramatic developmental process allows a minute isolated fragment of $B$. leachii's vascular system, or a colony excised of all adults, to restore a functional animal in as little as 10 days. In addition to this exceptional regenerative capacity, $B$. leachii can reproduce both sexually, through a tadpole larval stage, as well as asexually through palleal budding. Thus, three alternative developmental strategies lead to the establishment of filterfeeding adults. Consequently, B. leachii is particularly well suited for comparative studies on regeneration and should provide novel insights into regenerative processes in chordates.

Here, after a short introduction on regeneration, we overview the biology of B. leachii as well as the current state of knowledge on WBR in this species and in related species of tunicates. Finally, we highlight the possible future directions that research might take in the study of WBR, including thoughts on technological approaches that appear most promising in this context. Overall, we provide a synthesis of the current knowledge on WBR in B. leachii to support research in this chordate species. 


\section{Introduction}

Tunicates are marine invertebrates considered to be the closest living invertebrate relative to the vertebrate subphylum (Delsuc et al. 2006). Despite a drastically different body plan during their adult stage, the tunicate larvae possess typical chordate features, including a pharynx with gill slits, a notochord, a dorsal nerve cord and muscle segments (Millar 1971; Satoh 2003, 2011). Thus, the study of these animals may offer a unique evolutionary perspective into a wide range of biological processes conserved within the phylum Chordata. Colonial tunicates are also established models for other important biological processes including allorecognition, chimerism, ageing and angiogenesis (Rinkevich and Weissman 1987; Saito et al. 1994; Paz and Rinkevich 2002; Kürn et al. 2011; Gasparini et al. 2014; Voskoboynik and Weissman 2015; Kassmer et al. 2016). Of particular interest, these modular organisms are the only known chordates that can undergo whole-body regeneration (WBR), whereby a fully functional adult is restored from a minute portion of their vascular system containing as little as 100-200 circulating blood cells in a short period of about 10 days (Rinkevich et al. 1995, 2007b; Voskoboynik et al. 2007; Brown et al. 2009).

Multicellular animals capable of varying degrees of regeneration are distributed widely throughout the Metazoa, suggesting that this biological phenomenon has an ancestral origin (Sánchez Alvarado and Tsonis 2006; Bely and Nyberg 2010). However, regeneration ability inversely correlates with the tissue complexity of an organism (Sánchez Alvarado 2000). Among vertebrates, most species only present a limited regeneration capacity with few mammals, teleost fishes and urodele amphibians that can regenerate either body parts or organs following injury (Roy and Gatien 2008; Poss 2010; Seifert et al. 2012; Jaźwińska and Sallin 2016). Although the study of these organisms has brought an extensive knowledge on patterning and cellular programs required for regeneration of severely injured organs, no vertebrate has yet been shown to undergo WBR. Therefore, deciphering the mechanisms underlying regeneration in the closely related Tunicata 
subphylum might provide new insights into shared principles of cellular plasticity in adult chordates. Consequently, colonial ascidians have emerged as model systems for the study of WBR and other regenerative processes in chordates (Tiozzo et al. 2008a; Kürn et al. 2011; Voskoboynik and Weissman 2015; Kassmer et al. 2016). Here we focus on WBR in Botrylloides leachii (class Ascidiacea, order Stolidobranchia, family Styelidae), a colonial sedentary marine chordate, first identified 200 years ago along the British coasts and since found worldwide (Savigny 1816; Michaelsen and Stephenson 1934; Brewin 1946; Brunetti 1976; Myers 1990; Tamilselvi and Sivakumar 2011). 


\section{The biology of Botrylloides leachii}

B. leachii is a sessile suspension-feeding colonial ascidian that can commonly consist of hundreds 2-3 mm long adults, termed zooids, organized in a series of ladder-like parallel rows, known as systems (Fig. $1 \&$ 2A; Savigny 1816). The colony remains attached to its substrate, typically on seagrass or rocks in the shallow sub-tidal zone, through a semi-transparent gelatinous matrix called tunic (Savigny 1816; Berrill 1947; Rinkevich et al. 1993). B. leachii zooids feed by filtering food particles from seawater using a thin sheet of mucus that covers their pharyngeal baskets (Millar 1971; Sawada et al. 2001). This mucus is produced by the endostyle, spread over the gill slits of the basket by ciliary movements and collected by dorsal lamina, which eventually propels it into the stomach. Seawater is drawn through the oral siphons of the zooids, pushed through the gill slits by the contraction of the animal's body and finally expelled, along with any waste, through an excurrent siphon shared by the zooids within a system (Millar 1971; Sawada et al. 2001).

While each zooid has an independent heart and an open circulatory system, the entire colony shares a common vasculature that is embedded in the tunic and closed at its periphery by terminal ampullae, the contractile blind ends of marginal vessels (Fig. 1; Mukai et al. 1978). Originating from the ectoderm, this vasculature has been shown to resemble that of vertebrates, and even respond to human factors that stimulate angiogenesis such as vascular endothelial growth factor (Gasparini et al. 2008, 2014; Tiozzo et al. 2008b). B. leachii blood (haemolymph) is mostly colourless and composed of nine cell types with functions incipient to that of vertebrate blood cells, which can be classified into five cell lineages (Cima et al. 2002; Blanchoud et al. 2017): undifferentiated cells (haemoblasts), immunocytes (hyaline amebocytes, macrophage-like cells, granular amebocytes, morula cells), mast cell-like cells (granular cells), transport cells (compartment amebocytes, compartment cells) and storage cells (pigment cells, nephrocytes). It 
appears that there may be multiple niche sites for blood cell production, including cell clusters located near the endostyle (Voskoboynik et al. 2008; Brown et al. 2009; Rinkevich et al. 2013; Lauzon et al. 2013).

B. leachii zooids are viviparous hermaphrodites and can reproduce both sexually, to colonize new locations through a tadpole larval stage, or asexually, to expand the colony. This latter reproduction, also known as palleal budding or blastogenesis, is a cyclic phenomenon that starts through the consecutive budding and invagination of the outer epithelial mantle of a zooid (Fig. 1A; Berrill 1947). Typically, budding occurs on both sides of each adult within the colony and therefore produces two offspring per zooid. Each colony harbours at any time three generations of colonial modules: the zooids, the primary buds and the budlets (secondary buds, located on the primary bud). Blastogenesis can be classified into several developmental stages, culminating by the ‘takeover' phase (lasting about $12 \mathrm{~h}$ ) where all functional zooids in a colony are simultaneously resorbed by cellular waves of apoptosis and phagocytosis (Manni et al. 2007; Rinkevich et al. 2013; Gutierrez and Brown 2017). The primary palleal buds then mature into functional filter-feeding zooids to replace the previous generation, while budlets develop into primary buds that will themselves carry a new generation of budlets. The duration between two consecutive cycles of takeover depends on water temperatures but typically takes about a week at $18-20{ }^{\circ} \mathrm{C}$ (Berrill 1947).

In a sexually mature Botrylloides colony, which occurs upon favourable environmental conditions (Brunetti 1976; Rinkevich et al. 1993), male and female gonads are situated side by side in every single zooid (Berrill 1947; Millar 1971; Mukai 1977; Mukai et al. 1987). Both gonads require multiple blastogenic cycles to reach maturity (Kawamura et al. 2011). Ovulation takes place following the opening of the oral siphons during the takeover phase of blastogenesis (Zaniolo et al. 1994). Autogamy is avoided under natural conditions by a temporal delay between this release of the eggs and the discharge of sperm, thus providing time for external fertilization (Mukai et al. 1987). Fertilized eggs develop viviparously within brood pouches located inside the tunic in 
between zooids (Mukai 1977). The embryo then follows a stereotypical ascidian process of embryonic development (Mukai et al. 1987; Brown and Swalla 2012) whereby a motile larva is produced within a week and released to the environment. The tadpole eventually settles on an appropriate substrate and undergoes metamorphosis to give rise to a young adult (called an oozooid) that in turn will produce daughter zooids through blastogenesis (Fig. 1B; Berrill 1947).

To resist to adverse environmental conditions, colonial ascidians have rapid healing capacity in response to local injuries (Fig. 1C). For instance, bleeding from the vasculature stops in a few seconds from haemolymph aggregation and vessel contractions after lesion (Blanchoud et al. 2017); adults can heal in as little as one day from a localized surgical incision performed to access germ cells (Milkman 1967); and restoration of ablated vessels requires less than two days to complete (Tiozzo et al. 2008b). Albeit incompletely studied, B. leachii during healing expresses genomic markers similar to those observed in vertebrate wound healing and involves an initial cellular response through the infiltration of cytotoxic cells followed by clearing of the debris by macrophage-like cells (Zondag et al. 2016; Blanchoud et al. 2017). On top of this healing mechanism, B. leachii colonies can undergo WBR from a minute fragment of their vascular tissue to compensate for the loss of all their zooids (Fig. 1D; Rinkevich et al. 1995). 


\section{Current state of research on WBR in B. leachii}

WBR in Botrylloides leachii was first observed by Rinkevich et al. who were also the first to coin the term WBR to this type of regeneration in colonial ascidians (Rinkevich et al. 1995). Using light microscopy and histological sections, Rinkevich and colleagues described the sequence of events leading to the regeneration of a fully function zooid from an isolated fragment of the vascular system. Importantly, they observed that WBR will only be triggered following the loss of all zooids from the colony and may be started from as little as a single ampulla containing as few as 100-200 blood cells in just 10 days (Rinkevich et al. 1995). One single zooid per colonial fragment will invariably regenerate despite the transient appearance of multiple regeneration niches, suggesting the existence of an uncharacterised competition mechanism. WBR has since then been first classified into three distinctive phases (dynamic reorganization in vessel architecture, initial stages of regeneration, the race for predominance; Rinkevich et al. 2007b) that were then further refined into the following six stages (Zondag et al. 2016):

Stage 0 , injury of the colony (0 hour post ablation (hpa))

After the initial ablation, haemolymph loss is stopped in less than $30 \mathrm{~s}$ by a combination of tissue contraction and haemocyte aggregation. Flow will then restart after a pause shorter than 10 min, driven by spatially and temporally synchronized ampullar contractions (Rinkevich et al. 1995; Blanchoud et al. 2017).

Stage 1 , healing of the injury (15 hpa)

Retinoic acid (RA) expressing macrophage-like cells are observed adjacent to aggregates of small cytotoxic (morula) immune cells (Rinkevich et al. 2007b). RA signalling is essential for WBR as both its chemical and molecular disruptions inhibit regeneration (Rinkevich et al. 2007b). Morula 
cells massively infiltrate into the tunic matrix and an increase in the populations of haemoblasts takes place (Blanchoud et al. 2017). Differential gene expression analysis of the transcriptome shows up-regulation of genes involved in cell-cell and cell-matrix adhesion, apoptotic processes, metabolic and cellular processes, as well as of developmental signalling pathways including WNT, TGF- $\beta$ and Notch (Zondag et al. 2016). These biological processes are suggestive of a global switch in gene expression for the activation of healing that includes RA signalling.

Stage 2, remodelling of the vascular system (24 hpa)

Vascular remodelling starts with a change in shape of the terminal ampullae, the contraction of the isolated vascular system, and the creation of novel tunic vessels (Rinkevich et al. 1995, 2007b; Blanchoud et al. 2017). This remodelling is blocked by RA inhibition (Rinkevich et al. 2007b). Giant cells can be observed throughout the vascular system and retinoic acid receptor (RAR) expression starts (Rinkevich et al. 2007b). So-called dormant cells, which line the internal epithelium of the blood vessels, express the evolutionarily conserved stemness marker Piwi, and the cell proliferation indicator proliferating cell nuclear antigen (PCNA) (Rinkevich et al. 2010). Inhibition of Piwi, both chemically as well as using gene knockdown by RNA interference, prevents WBR but not the remodelling of the vascular tissue (Rinkevich et al. 2010, 2013). Macrophage-like cells conglomerates express a Trypsin-like serine protease (TrSP) (Rinkevich et al. 2007a).

Stage 3, condensation of the ampullae (72 hpa)

The fully contracted vascular system is colonized by various regeneration niches, defined as spherical aggregates of cells within the vascular lumen (Fig. 2B; Rinkevich et al. 1995, 2007b; Blanchoud et al. 2017). These blastula-like structures vary in size (10-95 $\mu \mathrm{m}$ in diameter), cell numbers (20-200), and sphericity (Fig. 2C; Rinkevich et al. 2007b). Piwi+ cell numbers increases within lumens of blood vessels as regeneration proceeds, colonizing all regeneration niches and 
expressing PCNA (Rinkevich et al. 2010). Chemically blocking cell cycle entry using Mitomycin C restricts the Piwi+ to the internal epithelium, preventing their expansion in the vessel lumen (Rinkevich et al. 2010). RAR gene expression specifically demarcates all these regeneration sites (Rinkevich et al. 2007b). Additional supplementation of RA to regenerating fragments results in an accelerated regeneration and the restoration of multiple functional zooids (Rinkevich et al. 2007b). Analysis of differentially expressed sequence tags (ESTs) identifies an increase of immune-related transcripts, including proteases such as $\operatorname{TrSP}$ that is expressed in the regeneration niches (Rinkevich et al. 2007a). This EST screen also highlighted genes belonging to major signalling pathways, including Notch/Delta, JAK/STAT, protein kinases, nuclear receptors, Ras oncogene family members, G-Protein coupled receptor (GPCR) and transforming growth factor beta (TGF- $\beta$ ) (Rinkevich et al. 2008). Representative transcripts of these signalling pathways are expressed specifically during the early stages of regeneration in the conglomerates of round haemocytes within regeneration niches (Rinkevich et al. 2008). A large increase in phagocytic cells is also observed at this stage (Fig. 2D; Blanchoud et al. 2017).

Stage 4, establishment and development of regeneration niches (144 hpa)

Piwi+ cell numbers consistently increases within the lumens of blood vessels where they proliferate until their later differentiation (Rinkevich et al. 2010). Regeneration niches develop by invagination of their vesicles' wall, which will develop into the various chambers and organs of the zooid (Rinkevich et al. 2007b). Representative transcripts of the major signalling pathways present during stage 3 disappear from developing buds, becoming restricted to incipient niches (Rinkevich et al. 2008). Transcriptome analysis highlights the up-regulation of pathways required for protein synthesis, biogenesis and the organisation of cellular components (Zondag et al. 2016). Transport, mast-cell like, and storage cells are at their lowest during this stage while macrophage-like cells remain at a higher proportion than in uninjured colonies (Blanchoud et al. 2017). 
Stage 5, fully regenerated zooid (240 hpa)

A single fully functional zooid is regenerated, irrespective of the original size and content of the isolated vascular system (Rinkevich et al. 1995, 2007b). This zooid is larger and rounder than usual, displaying the palleal buds expected from an uninjured adult but without any visible gametes (Rinkevich et al. 1995, 2007b; Blanchoud et al. 2017). Regular blastogenic cycles will ultimately result in generations of zooids that display sexual activities (B. Rinkevich, unpublished data).

Overall, WBR in B. leachii has unique regeneration characteristics when compared to other representative models (Rinkevich et al. 2007b). These are highlighted by the presence of multiple initiation sites in regeneration niches, a systemic induction through retinoic acid, the participation of circulating haemocytes that restore both germ line and soma, as well as the intra-organismic competition between regeneration niches that lead to a single survivor. 


\section{Inferences from WBR and asexual reproduction in other colonial ascidians}

Although tunicates have been shown to undergo faster genomic evolution than vertebrates (Berna and Alvarez-Valin 2014), they have also been shown to share numerous conserved biological mechanisms. Consequently, data from other tunicates, and from related colonial ascidians in particular, could be helpful to draw pertinent inferences to design novel experiments for studying the mechanisms underlying WBR in B. leachii.

\subsection{Differences in WBR ability between colonial ascidians}

Despite their similarities in morphology and life cycle, colonial ascidians present variations in their regenerative capacity, even within the genus Botrylloides (Fig. 3; Rinkevich et al. 1993). Indeed, Botrylloides lenis, Botryllus delicates and Botryllus primigenus (Fig. 3A) are yet the only documented botryllid ascidians that undergo spontaneous vascular budding, whereby buds develop from their vascular epithelium, at the morphological level similarly to WBR in B. leachii (Oka and Watanabe 1959; Saito and Watanabe 1985; Okuyama and Saito 2001). In Symplegma brakenhielmi, an unsynchronized blastogenic species, vascular budding is the main source of asexual development (Gutierrez and Brown 2017), similarly to Clavelina lepadiformis where isolated fragments of stolon typically regenerate functional adults within 8 days (Berrill and Cohen 1936).

By contrast, in B. leachii, Botrylloides violaceus and Botryllus schlosseri, WBR occurs only if no bud, no zooid and even no fragment of zooid remain present in the tissue (Fig. 3B-D; Rinkevich et al. 1995; Voskoboynik et al. 2007; Brown et al. 2009). For the successful regeneration of $B$. schlosseri colonies, the vascular system must be intact with an active blood flow and the zooids must be ablated during the takeover stage of blastogenesis (Fig. 3B; Voskoboynik et al. 2007). In addition, B. schlosseri WBR goes through several generations of morphologically 
abnormal zooids before forming a normal colony (Voskoboynik et al. 2007); whereas, in B. leachii, one morphologically normal zooid directly forms at the completion of WBR (Fig. 3C; Rinkevich et al. 1995; Zondag et al. 2016; Blanchoud et al. 2017). Likewise, B. violaceus WBR can be initiated at any point during its blastogenic cycle, but leads in this species to the restoration of multiple zooids (Fig. 3D; Oka and Watanabe 1959).

\subsection{Insights from asexual reproduction}

Asexual reproduction and regeneration capacity has been shown to correlate (Rychel and Swalla 2009), and even to be convergent processes in tunicates (Kawamura et al. 2008), thus raising the possibility that both mechanisms could have a similar cellular origin. Compound ascidians present a wide variety of forms of asexual reproduction (palleal, vascular, stolonial, pyloric and strobilation budding; Brown and Swalla 2012), and various degrees of regenerative capacities (subsection 4.1). Furthermore, early buds express a range of precursor lineage markers such as Piwi, Pl10, Raldh, Vasa and SoxB1, providing additional evidence that they have a progenitor cell identity (Rosner et al. 2009, 2013; Brown et al. 2009; Rosner and Rinkevich 2011). It is believed that, at least in botryllid ascidians, primordial germ cells develop during late embryogenesis (Rosner et al. 2013).

In Perophora viridis, budding of irradiated colonies could be rescued by the injection of a sub-population of healthy blood cells physiologically similar to haemoblasts (Freeman 1964). Similarly, in Botryllus schlosseri, injection of previously enriched circulating stem-like cells can infiltrate both the germ line as well as the soma of host colonies (Laird et al. 2005). Interestingly, injection of immobile cells located around the endostyle can also induce long-term infiltration of the host B. schlosseri colony (Voskoboynik et al. 2008). However, single-cell injections have shown that these cells are unable to colonize both lineages, suggesting the existence of two distinct stem populations (Laird et al. 2005), a conclusion supported by studies on chimeric organisms (Stoner et 
al. 1999). The stemness of these cell lineages is supported by the observed high telomerase activity during bud development (Laird and Weissman 2004). Alternatively in Polyandrocarpa misakiensis, asexual budding is based on transdifferentiation of atrial epithelium cells (Kawamura and Fujiwara 1994, 1995; Kawamura et al. 2018). Similarly, in the asexual reproduction of Polycitor proliferus through strobilation, differentiated epicardium is the origin of the multi-potent stem cells (Kawamura et al. 2008). Altogether, these results suggest the existence of a several multi-potent stem cells that are involved in asexual reproduction in colonial ascidians.

\subsection{The origin of the progenitor cells driving WBR}

In botryllid ascidians, two populations of circulatory adult pluripotent stem cells have been identified (germ line and somatic stem cells; Stoner et al. 1999; Laird et al. 2005; Voskoboynik et al. 2008; Rosner et al. 2009). However, they are not the only cellular players as WBR in B. leachii requires the activation of dormant Piwi+ adult stem cells that line the internal vasculature epithelium of blood vessels, but not that of circulatory haemoblasts (Rinkevich et al. 2010). Nevertheless, the origin of these stem-like cells remains to be determined, as they could not be identified in uninjured colonies (Rinkevich et al. 2010). Therefore, an early role for circulatory cells in WBR cannot be totally rejected.

In the closely related species B. violaceus, PCNA+/Piwi+ circulatory haemocytes surround the site where WBR takes place and their number slowly decreases as regeneration of the adult occurs, suggesting that they are the main population of progenitor cells for WBR in this species (Brown et al. 2009). In addition, in the more distant S. brakenhielmi, circulating undifferentiated cells expressing the mitotic marker phospho-histone H3 are involved in a vascular budding process that also takes place after ablation of the adult zooids (Gutierrez and Brown 2017). By contrast, the cells providing the potential for WBR in $B$. schlosseri have been shown to be fixed to the vascular 
wall (Milkman 1967) and no Piwi+ cells are present in regeneration niches during B. primigenus WBR (Sunanaga et al. 2010).

One potential explanation for the observed developmental emancipation during WBR is the absence of colonial control. Indeed, experimental manipulations in which buds and zooids were surgically removed and placed under in vitro conditions, away from any discrete colonial regulatory cues, induced the resurgence of developmental processes otherwise masked by undetermined colonial controls (Rabinowitz and Rinkevich 2003, 2004, 2011; Rabinowitz et al. 2009). For instance, excised senescent zooids stopped their degeneration, extended their lifespan from a few hours to one month and produced de novo epithelial monolayers (Rabinowitz and Rinkevich 2004). In S. brakenhielmi, a potentially weaker colonial control, as suggested by the absence of developmental synchronization, might permit the observed spontaneous occurrence of WBR.

Consequently, WBR in colonial ascidians appears to utilize a variety of progenitor cells and developmental processes. Identifying the origins of multi-potent and stem-like cells and regulatory mechanisms is of particular interest to further understand how WBR is activated.

\subsection{The role of immune associated cells during WBR}

Gene expression for components of the complement system (C3b, C-type lectin) are upregulated during WBR (Rinkevich et al. 2007a; Zondag et al. 2016), potentially for their known roles in immune cells recruitment and phagocytosis stimulation (Murphy 2012). Macrophages and the complement system function together in other biological systems to promote cell proliferation and tissue remodelling (Ohashi et al. 1999; Davidson and Swalla 2002; Voskoboynik et al. 2004; Roberts et al. 2007), two processes important for successful WBR. In addition, a dramatic increase in the fraction of circulating macrophage-like cells during WBR in B. leachii suggests an important role for these immune cells during regeneration (Fig. 2D; Blanchoud et al. 2017). Interestingly, macrophage-like cells are also involved during the reactivation phase after aestivation in $B$. leachii 
(Burighel et al. 1976), as well as during the takeover stage of blastogenesis in B. schlosseri where they are involved in the degeneration of the apoptotic organs by coordinating death and clearance signals (Lauzon et al. 2002, 2013; Voskoboynik et al. 2004; Franchi et al. 2016). Macrophageinduced phagocytosis generates an oxidative stress that should lead to cell lethality when performed at the scale observed during takeover, but which is instead balanced by the coordinated expression of anti-oxidant genes (Franchi et al. 2017). Moreover, the ablation of resorbing zooids during takeover prevents the full-sized development of the next generation, while ablation of all but one daughter bud leads to its hyperplasia (Lauzon et al. 2002).

Altogether, these results suggest an essential and regulated involvement of macrophage-like cells in WBR. Some of the above results also suggest that macrophage-like cells could be a general mechanism for removing cellular debris and potentially providing a source of nutrients for developing buds (Lauzon et al. 2002, 2013). In addition, this model would explain the resorption of the unsuccessful regeneration niches during the growth expansion phase of the successful bud to provide it with essential nutrients (Rinkevich et al. 1995; Blanchoud et al. 2017).

\subsection{Genes involved in WBR have multiple roles in colonial ascidian}

Several studies focused on gene expression characteristic to the WBR, yet many of these genes also play roles in other developmental processes of tunicates. For example, the identification of genes involved with both B. leachii WBR (Rinkevich et al. 2007a), budding in P. misakiensis and blastogenesis in B. schlosseri (Oren et al. 2007); B. Rinkevich, unpublished data) highlighted a large variety of genes from protein families such as serine and trypsin proteases, serine and trypsin inhibitors, coagulation factors, lectins, cathepsins and metalloendopeptidases as well as genes involved in signal transduction pathways (Rosner et al. 2014). However, this wide panel of molecular functions suggests that most of these genes are not specific markers of WBR but are rather co-opted from other developmental processes. 
An example of such diversification of function is the Von Willebrand factor (VWF), which is expressed in B. leachii WBR (Rinkevich et al. 2007a), in B. schlosseri allorecognition and blastogenesis (Oren et al. 2007); B. Rinkevich, unpublished data), in Boltenia villosa metamorphosis (Davidson and Swalla 2002; Roberts et al. 2007), in Ciona robusta metamorphosis (Nakayama et al. 2002; Chambon et al. 2007) and in P. misakiensis budding (Kawamura et al. 1998, 2006). A second instance of multiple roles for WBR genes is that of the DEAD-box RNA helicase Pl10, which is expressed in B. leachii WBR by macrophage-like cell (Rinkevich et al. 2010), in B. schlosseri during blastogenesis and embryogenesis (Rosner et al. 2006; Voskoboynik et al. 2008), as well as in more distance species such as in the neoblasts of the planarian Dugesia japonica and the Hydra magnipapillata multipotent interstitial stem cells (Rosner and Rinkevich 2007).

Overall, these genomic analyses suggest a large-scale co-option of developmental genes during WBR and highlight the current lack of markers specific to WBR in colonial ascidians. 


\section{Future directions}

While a wide range of multicellular organisms possesses powerful regeneration capacities (e.g. members of the phyla Porifera, Cnidaria, Platyhelminthes, Echinodermata, Bryozoa; Bely and Nyberg 2010), WBR in colonial ascidians is a unique phenomenon in the Chordata that can provide a special phylogenetic perspective into this process. In addition, the presence of other colonial ascidians with a limited or even an absence of regenerative capacity is particularly well-suited for comparative studies (Tiozzo et al. 2008a). Consequently, B. leachii is an appealing system for the study of chordate regeneration. Yet, when compared to other models of regeneration, relatively little is known about the nature of this process.

To understand WBR in B. leachii, researchers need to understand its major components. Any regenerative process requires at least the integration of: (a) cellular building blocks, including but not restricted to stem cells; (b) a sufficient supply of nutrient and oxygen, typically in the form of a vascular network; (c) the deposition of an extracellular matrix to create an adequate developmental environment; and (d) correct positional information to dictate morphogenesis (Rinkevich and Rinkevich 2013). Having all above in mind, we foresee three major steps in the future of this research:

1. Identification of the cellular origin of WBR. Although essential stem-like cells have been identified in the lining of the vascular epithelium, the origin of these cells remains unknown. Identifying this origin will be of major importance for understanding how their stem-like state is achieved and for the potential reactivation of similar processes in vertebrates. It is also important to identify the roles of circulating cells in the formation of regeneration niches and of developing zooid (Rinkevich et al. 1995, 2007b). 
2. Characterization of WBR at the morphological level. WBR in botryllid ascidians differs at several morphological levels from the regeneration regularly studied in vertebrate model organisms. One example is the appearance of multiple regeneration niches whereas vertebrate regeneration typically originates from a single blastema. Understanding the morphogenesis of the developing regeneration niches is ancillary to identifying common regenerative strategies and to establishing a unified theory for metazoan regeneration (Rinkevich and Rinkevich 2013).

3. Characterisation of WBR at the genetic level. Dissection of the molecular and genomic components involved during WBR through perturbation analyses is key to deciphering the mechanisms underlying chordate WBR. Indeed, cross-phyla studies have indicated that the phenomenon of regeneration, while variable at most levels of biological design, portrays extensive conservation of developmental signalling pathways (Sánchez Alvarado and Tsonis 2006).

The common dogma supports the notion that regeneration is a primeval attribute of metazoans (Brockes et al. 2001; Bely and Nyberg 2010; Slack 2017). However, it remains to be determined whether regeneration has emerged along a unified continuum (Rinkevich and Rinkevich 2013), or independently as multiphyletic convergent responses to a variety of biological and environmental settings. Irrespective of the nature of this origin, the high degree of variation observed in model organisms as well as the assortment of cellular sources involved in regeneration attest that it is a highly complex biological phenomenon (Tsonis 2000; Tiozzo et al. 2008a; Rychel and Swalla 2009; Bely and Nyberg 2010; Galliot 2013; Jaźwińska and Sallin 2016). Consequently, obtaining a more complete picture of WBR in B. leachii will likely be challenging. Fortunately, future research will greatly benefit from existing studies in related species, novel multidisciplinary approaches as well as from advances in technology. Cell labelling and live-cell tracking of regenerating tissue fragments will be relevant to understand cell migrations and lineages. The precision of these labelling techniques will further benefit from the development of molecular 
markers specific to B. leachii cell fates and tissues. Single-cell RNA sequencing, proteomics and genomics will provide the unbiased identification of spatial and temporal variations at the expression, transcription and protein level throughout regeneration. In addition, genome sequence will provide an essential basis for the development of transgenic lines and gene editing platforms such as the CRISPR/Cas9 gene technology, which has been successfully used in a wide range of animal systems including the tunicate Ciona robusta (Stolfi et al. 2014). Finally, establishment of inbred colonies, similar to those founded in Botryllus schlosseri (Rinkevich and Shapira 1998), will reduce inter-colony variability and provide a reference strain for future studies.

Overall, this will improve our understanding of regeneration strategies and will reveal the nature of regeneration processes that vary between closely related taxa. 


\section{Acknowledgements}

We would like to thank Aude Blanchoud for proofreading this review. SB was funded by the Swiss National Science Foundation (SNSF) grant number PZ00P3_17398. MJW was funded by a School of Biomedical Sciences Deans bequest grant. BR was funded by the Israel Academy of Sciences grant number 172/17. SB, MJW and BR were funded by a Royal Society of NZ Marsden fund grant (UOO1713). 


\section{Figures}

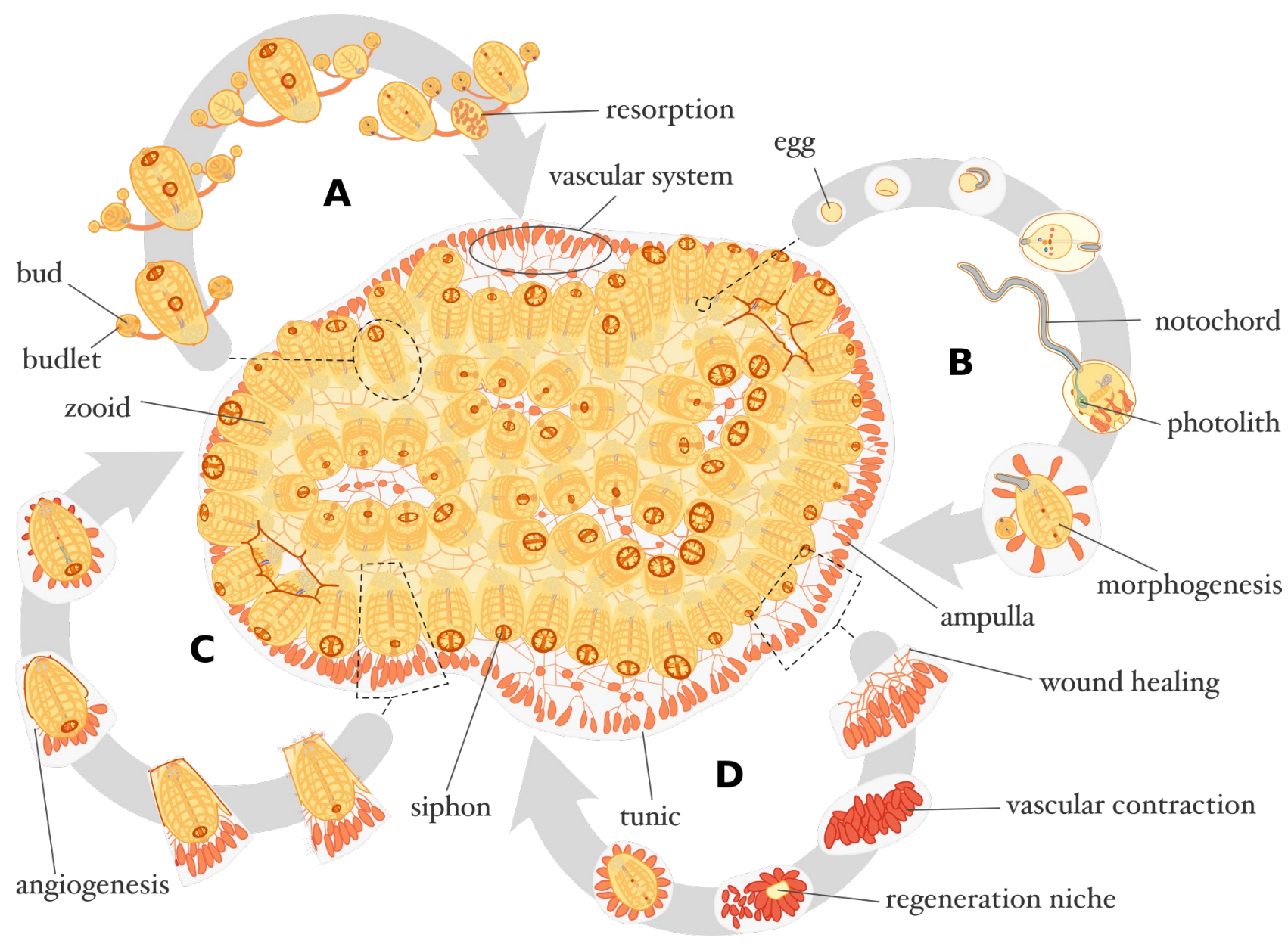

Figure 1. Botrylloides leachii schematic physiology. Top-view of a stereotypical colony composed of 72 zooids. (A) Blastogenic cycle of an adult zooid with two daughter buds and four budlets. (B) Viviparous sexual reproduction in B. leachii takes place inside the colony, larvae are released and undergo metamorphosis thereby initiating a new colony. (C) Healing of an injured adult zooid. (D) B. leachii WBR is initiated from an isolated fragment of vascular tissue. 

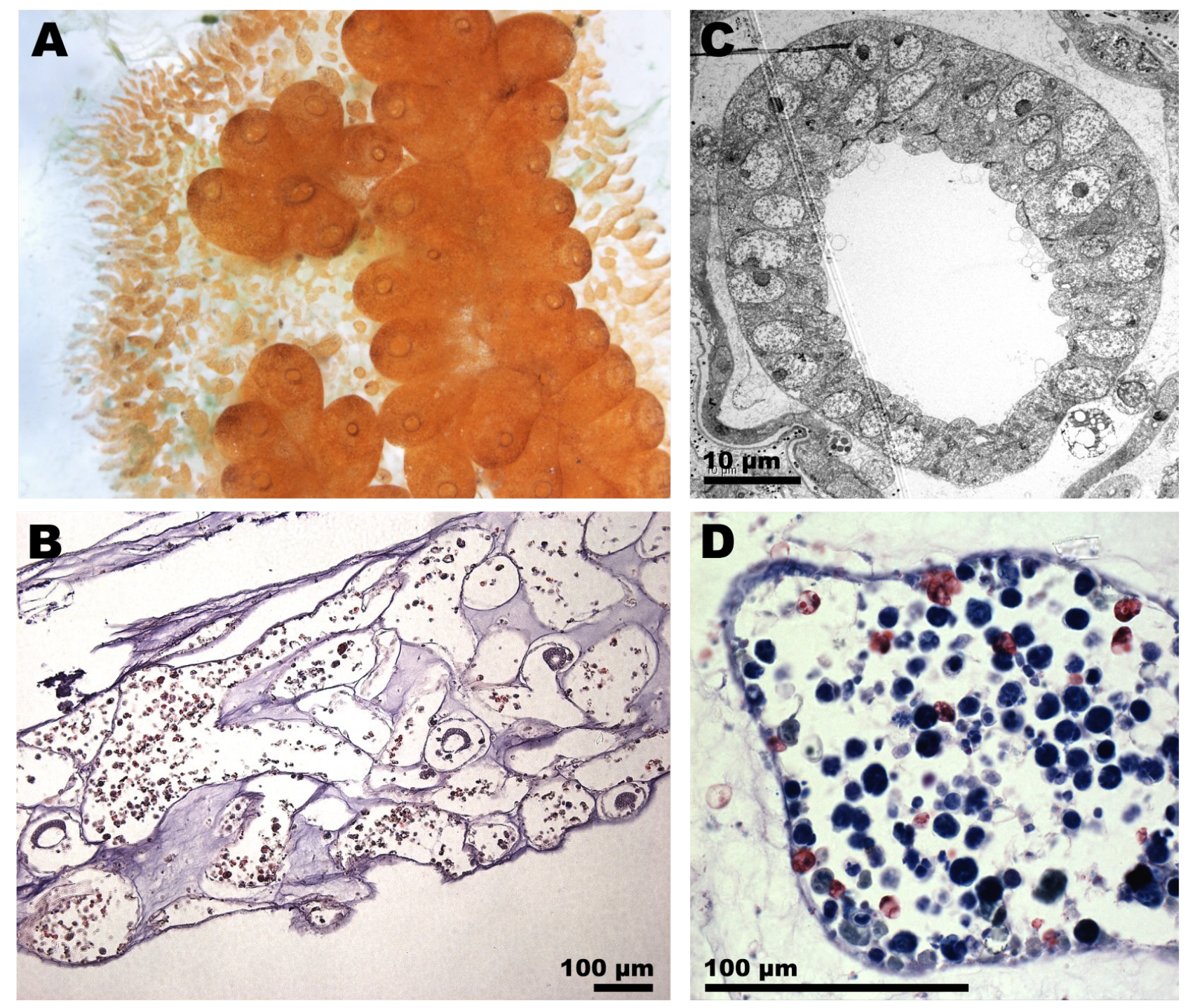

Figure 2. B. leachii WBR morphology. (A) Top-view of a portion of a Botrylloides leachii colony settled on a glass slide. Zooids are arranged in ladder-like structures. Peripheral and central ampullae are clearly visible in the tunic matrix as they harbor orange pigment cells. The inhalant siphons of the zooids are open and delineated by darker pigment cells. (B) Four regeneration niches at different developmental stages colonize the contracted vascular system at WBR stage 3 (H\&E stain). (C) Scanning electron microscope image of the first vesicular stage of WBR. (D) Macrophage-like cells (dark blue) compose the majority of the haemocytes in the vasculature at WBR stage 3 (Giemsa stain). 


\section{Colony}
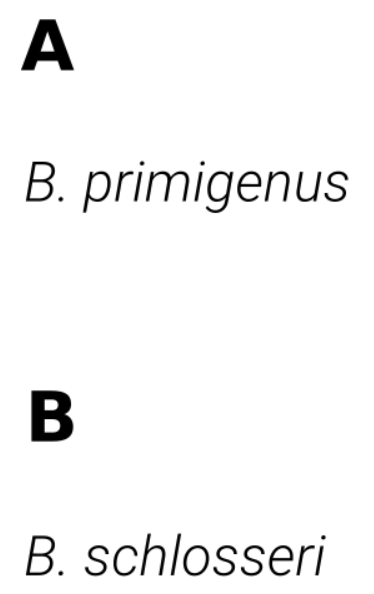

B. leachii
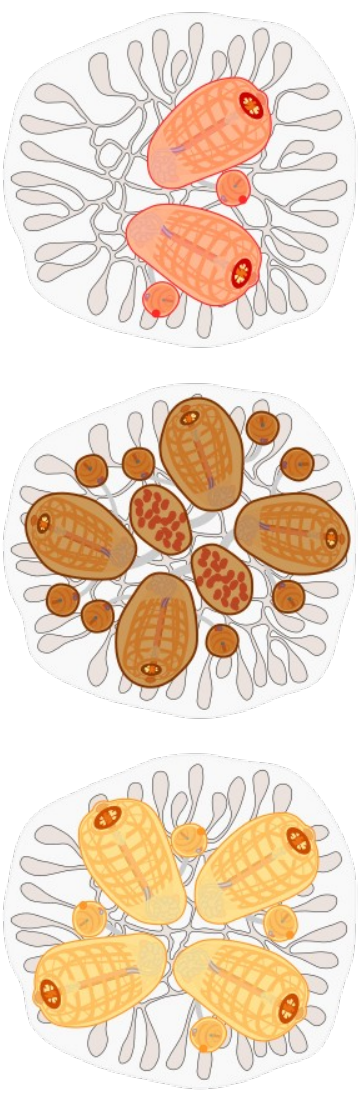

\section{D \\ B. violaceus}

Initiation
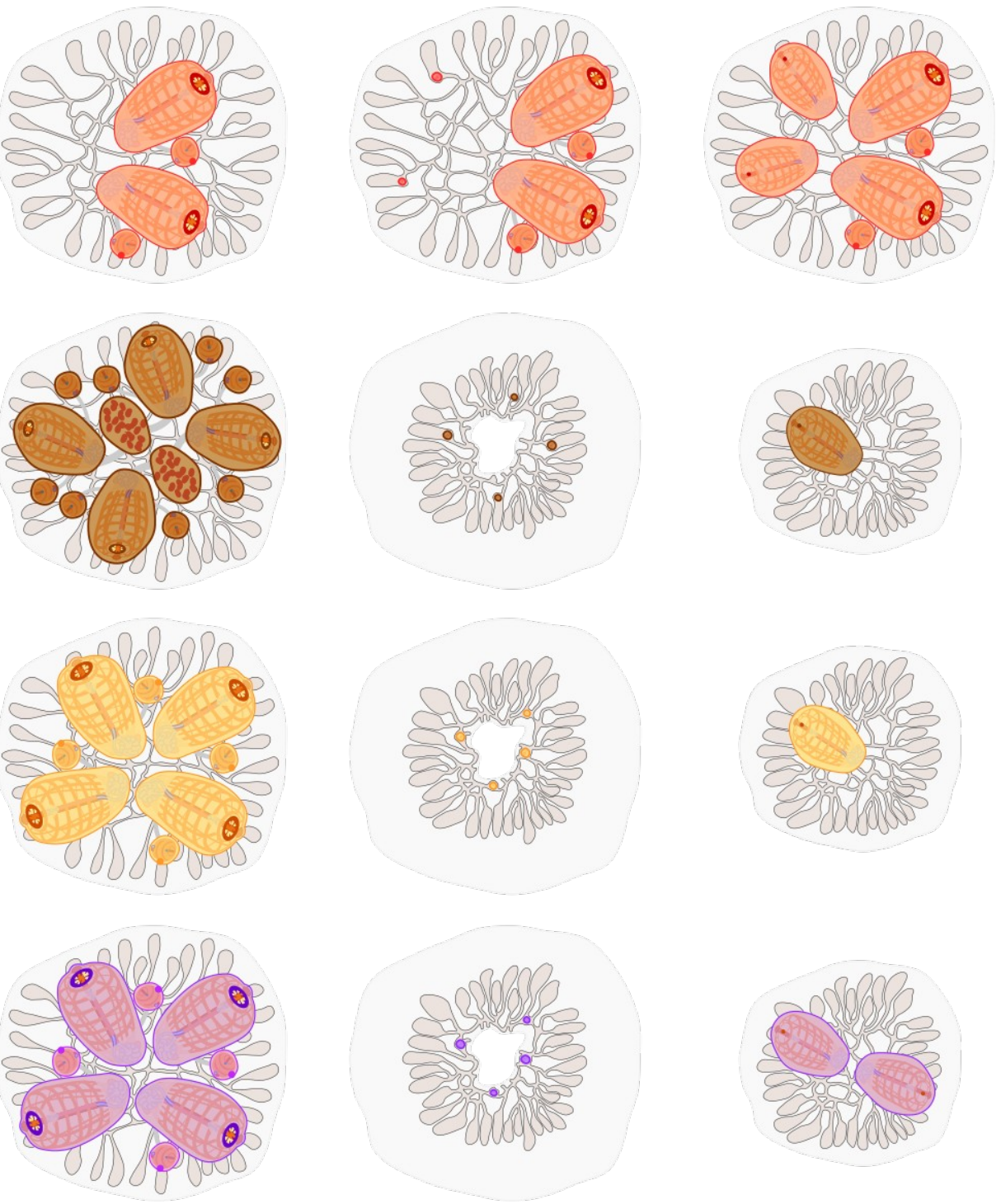

\section{Regeneration}
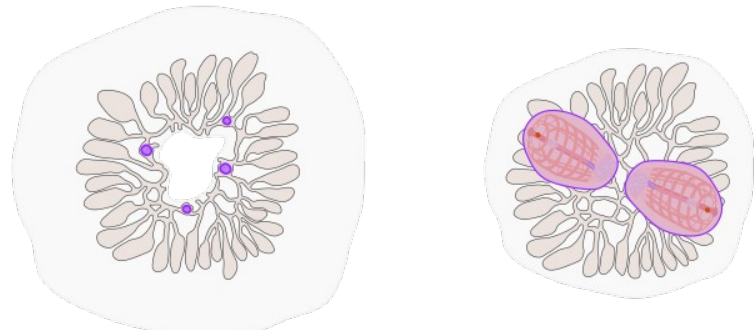

Figure 3. Schematic illustration of the variability of WBR in colonial ascidians. (A) Botryllus primigenus. Vascular budding occurs spontaneously at the base of multiple actively growing terminal ampullae, at the end of developmental stage $B$, leading to the maturation of potentially multiple zooids (Oka and Watanabe 1957). (B) Botryllus schosseri. Upon ablation of all zooids at developmental stage D (takeover), multiple regeneration niches are initiated at the base of terminal ampullae, leading to the maturation of one single zooid (Voskoboynik et al. 2007). (C) Botrylloides leachii. Upon ablation of all zooids, multiple regeneration niches are initiated throughout the vascular system, leading to the maturation of one single zooid (Rinkevich et al. 1995). (D) Botrylloides violaceus. Upon ablation of all zooids, multiple regeneration niches are initiated 
throughout the vascular system, leading to the maturation of potentially multiple zooids (Oka and Watanabe 1959). 


\section{References}

Bely AE, Nyberg KG (2010) Evolution of animal regeneration: re-emergence of a field. Trends Ecol Evol 25:161-170. doi: 10.1016/j.tree.2009.08.005

Berna L, Alvarez-Valin F (2014) Evolutionary genomics of fast evolving tunicates. Genome Biol Evol 6:1724-1738. doi: 10.1093/gbe/evu122

Berrill NJ (1947) The developmental cycle of Botrylloides. Q J Microsc Sci 88:393-407

Berrill NJ, Cohen A (1936) Regeneration in Clavelina lepadiformis. J Exp Biol 13:352-362

Blanchoud S, Zondag L, Lamare MD, Wilson MJ (2017) Hematological analysis of the ascidian Botrylloides leachii (Savigny, 1816) during whole-body regeneration. Biol Bull 232:143-157. doi: 10.1086/692841

Brewin BI (1946) Ascidians in the vicinity of the Portobello Marine Biological Station, Otago Harbour. Trans R Soc New Zeal 76:87-131

Brockes JP, Kumar A, Velloso CP (2001) Regeneration as an evolutionary variable. J Anat 199:311. doi: 10.1017/S0021878201008299

Brown FD, Keeling EL, Le AD, Swalla BJ (2009) Whole body regeneration in a colonial ascidian, Botrylloides violaceus. J Exp Zool B Mol Dev Evol 312:885-900. doi: 10.1002/jez.b.21303

Brown FD, Swalla BJ (2012) Evolution and development of budding by stem cells: Ascidian coloniality as a case study. Dev Biol 369:151-162. doi: 10.1016/j.ydbio.2012.05.038

Brunetti R (1976) Biological cycle of Botrylloides leachi (Savigny) (Ascidiacea) in the Venetian lagoon. Vie Milieu XXVI:105-122

Burighel P, Brunetti R, Zaniolo G (1976) Hibernation of the colonial ascidian Botrylloides leachi (Savigny): histological observations. Ital J Zool 43:293-301. doi: 10.1080/11250007609430146

Chambon J-P, Nakayama A, Takamura K, et al (2007) ERK- and JNK-signalling regulate gene networks that stimulate metamorphosis and apoptosis in tail tissues of ascidian tadpoles. Development 134:1203-1219. doi: 10.1242/dev.002220

Cima F, Perin A, Burighel P, Ballarin L (2002) Morpho-functional characterization of haemocytes of the compound ascidian Botrylloides leachi (Tunicata, Ascidiacea). Acta Zool 82:261-274. doi: 10.1046/j.1463-6395.2001.00087.x

Davidson B, Swalla BJ (2002) A molecular analysis of ascidian metamorphosis reveals activation of an innate immune response. Development 129:4739-4751

Delsuc F, Brinkmann H, Chourrout D, Philippe H (2006) Tunicates and not cephalochordates are the closest living relatives of vertebrates. Nature 439:965-968. doi: 10.1038/nature04336 
Franchi N, Ballin F, Ballarin L (2017) Protection from oxidative stress in immunocytes of the colonial ascidian Botryllus schlosseri: transcript characterization and expression studies. Biol Bull 232:45-57. doi: 10.1086/691694

Franchi N, Ballin F, Manni L, et al (2016) Recurrent phagocytosis-induced apoptosis in the cyclical generation change of the compound ascidian Botryllus schlosseri. Dev Comp Immunol 62:816. doi: 10.1016/j.dci.2016.04.011

Freeman G (1964) The role of blood cells in the process of asexual reproduction in the tunicate Perophora viridi. J Exp Zool 156:157-183. doi: 10.1002/jez.1401560204

Galliot B (2013) Regeneration in Hydra. In: eLS. John Wiley \& Sons, Ltd, Chichester, UK

Gasparini F, Burighel P, Manni L, Zaniolo G (2008) Vascular regeneration and angiogenic-like sprouting mechanism in a compound ascidian is similar to vertebrates. Evol Dev 10:591-605. doi: 10.1111/j.1525-142X.2008.00274.X

Gasparini F, Caicci F, Rigon F, et al (2014) Testing an unusual in vivo vessel network model: a method to study angiogenesis in the colonial tunicate Botryllus schlosseri. Sci Rep 4:6460. doi: 10.1038/srep06460

Gutierrez S, Brown FD (2017) Vascular budding in Symplegma brakenhielmi and the evolution of coloniality in styelid ascidians. Dev Biol 423:152-169. doi: 10.1016/j.ydbio.2017.01.012

Jaźwińska A, Sallin P (2016) Regeneration versus scarring in vertebrate appendages and heart. J Pathol 238:233-246. doi: 10.1002/path.4644

Kassmer SH, Rodriguez D, De Tomaso AW (2016) Colonial ascidians as model organisms for the study of germ cells, fertility, whole body regeneration, vascular biology and aging. Curr Opin Genet Dev 39:101-106. doi: 10.1016/j.gde.2016.06.001

Kawamura K, Fujiwara S (1994) Transdifferentiation of pigmented multipotent epithelium during morphallactic development of budding tunicates. Int J Dev Biol 38:369-377

Kawamura K, Fujiwara S (1995) Cellular and molecular characterization of transdifferentiation in the process of morphallaxis of budding tunicates. Semin Cell Dev Biol 6:117-126. doi: 10.1006/scel.1995.0017

Kawamura K, Hayata D, Fujiwara S, Yubisui T (1998) Serine protease inhibitors expressed in the process of budding of tunicates as revealed by EST analysis. J Biochem 124:1004-1012. doi: 10.1093/oxfordjournals.jbchem.a022192

Kawamura K, Kariya Y, Ono Y, et al (2006) Molecular collaborations between serpins and trefoil factor promote endodermal cell growth and gastrointestinal differentiation in budding tunicates. Dev Growth Differ 48:309-322. doi: 10.1111/j.1440-169X.2006.00865.x

Kawamura K, Sugino Y, Sunanaga T, Fujiwara S (2008) Multipotent epithelial cells in the process of regeneration and asexual reproduction in colonial tunicates. Dev Growth Differ 50:1-11. doi: 10.1111/j.1440-169X.2007.00972.x 
Kawamura K, Tiozzo S, Manni L, et al (2011) Germline cell formation and gonad regeneration in solitary and colonial ascidians. Dev Dyn 240:299-308. doi: 10.1002/dvdy.22542

Kawamura K, Yoshida T, Sekida S (2018) Autophagic dedifferentiation induced by cooperation between TOR inhibitor and retinoic acid signals in budding tunicates. Dev Biol 433:384-393. doi: 10.1016/j.ydbio.2017.08.023

Kürn U, Rendulic S, Tiozzo S, Lauzon RJ (2011) Asexual propagation and regeneration in colonial ascidians. Biol Bull 221:43-61. doi: 10.1086/BBLv221n1p43

Laird DJ, De Tomaso AW, Weissman IL (2005) Stem cells are units of natural selection in a colonial ascidian. Cell 123:1351-1360. doi: 10.1016/j.cell.2005.10.026

Laird DJ, Weissman IL (2004) Telomerase maintained in self-renewing tissues during serial regeneration of the urochordate Botryllus schlosseri. Dev Biol 273:185-194. doi: 10.1016/j.ydbio.2004.05.029

Lauzon RJ, Brown C, Kerr L, Tiozzo S (2013) Phagocyte dynamics in a highly regenerative urochordate: insights into development and host defense. Dev Biol 374:357-73. doi: 10.1016/j.ydbio.2012.11.006

Lauzon RJ, Ishizuka KJ, Weissman IL (2002) Cyclical generation and degeneration of organs in a colonial urochordate involves crosstalk between old and new: A model for development and regeneration. Dev Biol 249:333-348. doi: 10.1006/dbio.2002.0772

Manni L, Zaniolo G, Cima F, et al (2007) Botryllus schlosseri: a model ascidian for the study of asexual reproduction. Dev Dyn 236:335-52. doi: 10.1002/dvdy.21037

Michaelsen W, Stephenson TA (1934) The ascidians of the Cape Province of South Africa. Trans R Soc South Africa 22:129-163. doi: 10.1080/00359193409519335

Milkman R (1967) Genetic and developmental studies on Botryllus schlosseri. Biol Bull 132:229. doi: $10.2307 / 1539891$

Millar RH (1971) The biology of ascidians. Adv Mar Biol 9:1-100. doi: 10.1016/S00652881(08)60341-7

Mukai H (1977) Comparative studies on the structure of reproductive organs of four botryllid ascidians. J Morphol 152:363-379. doi: 10.1002/jmor.1051520307

Mukai H, Saito Y, Watanabe H (1987) Viviparous development in Botrylloides (compound ascidians). J Morphol 193:263-276. doi: 10.1002/jmor.1051930305

Mukai H, Sugimoto K, Taneda Y (1978) Comparative studies on the circulatory system of the compound ascidians, Botryllus, Botrylloides and Symplegma. J Morphol 157:49-78. doi: 10.1002/jmor.1051570105

Murphy K (2012) Innate immunity: The first lines of defense. In: Janeway’s immunobiology. Taylor \& Francis, Oxford, pp 37-73 
Myers PE (1990) Space versus other limiting resources for a colonial tunicate, Botrylloides leachii (Savigny), on fouling plates. J Exp Mar Bio Ecol 141:47-52. doi: 10.1016/00220981(90)90156-7

Nakayama A, Satou Y, Satoh N (2002) Further characterization of genes expressed during Ciona intestinalis metamorphosis. Differentiation 70:429-437. doi: 10.1046/j.14320436.2002.700805.x

Ohashi M, Kawamura K, Fujii N, et al (1999) A retinoic acid-inducible modular protease in budding ascidians. Dev Biol 214:38-45. doi: 10.1006/dbio.1999.9400

Oka H, Watanabe H (1959) Vascular budding in Botrylloides. Biol Bull 117:340. doi: $10.2307 / 1538913$

Oka H, Watanabe H (1957) Vascular budding, a new type of budding in Botryllus. Biol Bull 112:225-240. doi: 10.2307/1539200

Okuyama M, Saito Y (2001) Studies on Japanese botryllid ascidians. I. A new species of the genus Botryllus from the Izu Islands. Zoolog Sci 18:261-267. doi: 10.2108/zsj.18.261

Oren M, Douek J, Fishelson Z, Rinkevich B (2007) Identification of immune-relevant genes in histoincompatible rejecting colonies of the tunicate Botryllus schlosseri. Dev Comp Immunol 31:889-902. doi: 10.1016/j.dci.2006.12.009

Paz G, Rinkevich B (2002) Morphological consequences for multi-partner chimerism in Botrylloides, a colonial urochordate. Dev Comp Immunol 26:615-22

Poss KD (2010) Advances in understanding tissue regenerative capacity and mechanisms in animals. Nat Rev Genet 11:710-722. doi: 10.1038/nrg2879

Rabinowitz C, Alfassi G, Rinkevich B (2009) Further portrayal of epithelial monolayers emergent de novo from extirpated ascidians palleal buds. In Vitro Cell Dev Biol Anim 45:334-342. doi: 10.1007/s11626-009-9179-4

Rabinowitz C, Rinkevich B (2003) Epithelial cell cultures from Botryllus schlosseri palleal buds: accomplishments and challenges. Methods Cell Sci 25:137-48. doi: 10.1007/s11022-0042087-9

Rabinowitz C, Rinkevich B (2004) In vitro delayed senescence of extirpated buds from zooids of the colonial tunicate Botryllus schlosseri. J Exp Biol 207:1523-1532. doi: 10.1242/jeb.00899

Rabinowitz C, Rinkevich B (2011) De novo emerged stemness signatures in epithelial monolayers developed from extirpated palleal buds. Vitr Cell Dev Biol - Anim 47:26-31. doi: 10.1007/s11626-010-9357-4

Rinkevich B, Rinkevich Y (2013) The "Stars and Stripes” metaphor for animal regenerationElucidating two fundamental strategies along a continuum. Cells 2:1-18. doi: 10.3390/cells2010001 
Rinkevich B, Shapira M (1998) An improved diet for inland broodstock and the establishment of an inbred line from a colonial sea squirt (Ascidiacea). Aquat Living Resour 11:163-171. doi: 10.1016/S0990-7440(98)80113-7

Rinkevich B, Shlemberg Z, Fishelson L (1995) Whole-body protochordate regeneration from totipotent blood cells. Proc Natl Acad Sci U S A 92:7695-9

Rinkevich B, Shlemberg Z, Lilkerlevav T, et al (1993) Life-history characteristics of Botrylloides (Tunicata) populations in Akko Bay, mediterranean coast of Israel. Isr J Zool 39:197-212. doi: 10.1080/00212210.1993.10688712

Rinkevich B, Weissman IL (1987) A long-term study on fused subclones in the ascidian Botryllus schlosseri: the resorption phenomenon (Protochordata: Tunicata). J Zool 213:717-733. doi: 10.1111/j.1469-7998.1987.tb03736.x

Rinkevich Y, Douek J, Haber O, et al (2007a) Urochordate whole body regeneration inaugurates a diverse innate immune signaling profile. Dev Biol 312:131-46. doi: 10.1016/j.ydbio.2007.09.005

Rinkevich Y, Paz G, Rinkevich B, Reshef R (2007b) Systemic bud induction and retinoic acid signaling underlie whole body regeneration in the urochordate Botrylloides leachi. PLoS Biol 5:e71. doi: 10.1371/journal.pbio.0050071

Rinkevich Y, Rinkevich B, Reshef R (2008) Cell signaling and transcription factor genes expressed during whole body regeneration in a colonial chordate. BMC Dev Biol 8:100. doi: 10.1186/1471-213X-8-100

Rinkevich Y, Rosner A, Rabinowitz C, et al (2010) Piwi positive cells that line the vasculature epithelium, underlie whole body regeneration in a basal chordate. Dev Biol 345:94-104. doi: 10.1016/j.ydbio.2010.05.500

Rinkevich Y, Voskoboynik A, Rosner A, et al (2013) Repeated, long-term cycling of putative stem cells between niches in a basal chordate. Dev Cell 24:76-88. doi: 10.1016/j.devcel.2012.11.010

Roberts B, Davidson B, MacMaster G, et al (2007) A complement response may activate metamorphosis in the ascidian Boltenia villosa. Dev Genes Evol 217:449-458. doi: 10.1007/s00427-007-0157-0

Rosner A, Alfassi G, Moiseeva E, et al (2014) The involvement of three signal transduction pathways in botryllid ascidian astogeny, as revealed by expression patterns of representative genes. Int J Dev Biol 58:669-676. doi: 10.1387/ijdb.140114ar

Rosner A, Moiseeva E, Rabinowitz C, Rinkevich B (2013) Germ lineage properties in the urochordate Botryllus schlosseri - from markers to temporal niches. Dev Biol 384:356-74. doi: 10.1016/j.ydbio.2013.10.002

Rosner A, Moiseeva E, Rinkevich Y, et al (2009) Vasa and the germ line lineage in a colonial urochordate. Dev Biol 331:113-128. doi: 10.1016/j.ydbio.2009.04.025 
Rosner A, Paz G, Rinkevich B (2006) Divergent roles of the DEAD-box protein BS-PL10, the urochordate homologue of human DDX3 and DDX3Y proteins, in colony astogeny and ontogeny. Dev Dyn 235:1508-1521. doi: 10.1002/dvdy.20728

Rosner A, Rinkevich B (2011) VASA as a specific marker for germ cells lineage: In light of evolution. Trends Comp Biochem Physiol 15:

Rosner A, Rinkevich B (2007) The DDX3 subfamily of the DEAD box helicases: Divergent roles as unveiled by studying different organisms and in vitro assays. Curr Med Chem 14:2517-2525. doi: 10.2174/092986707782023677

Roy S, Gatien S (2008) Regeneration in axolotls: a model to aim for! Exp Gerontol 43:968-973. doi: 10.1016/j.exger.2008.09.003

Rychel AL, Swalla BJ (2009) Regeneration in hemichordates and echinoderms. In: Stem Cells in Marine Organisms. Springer Netherlands, Dordrecht, pp 245-265

Saito Y, Hirose E, Watanabe H (1994) Allorecognition in compound ascidians. Int J Dev Biol 38:237-247

Saito Y, Watanabe H (1985) Studies on Japanese compound styelid ascidians. IV. Three new species of the genus Botrylloides from the vicinity of Shimoda. Publ Seto Mar Biol Lab 30:227-240

Sánchez Alvarado A (2000) Regeneration in the metazoans: why does it happen? Bioessays 22:57890

Sánchez Alvarado A, Tsonis PA (2006) Bridging the regeneration gap: genetic insights from diverse animal models. Nat Rev Genet 7:873-884. doi: 10.1038/nrg1923

Satoh N (2003) The ascidian tadpole larva: comparative molecular development and genomics. Nat Rev Genet 4:285-95. doi: 10.1038/nrg1042

Satoh N (2011) Tunicate embryos and cell specification. In: eLS. John Wiley \& Sons, Ltd, Chichester, UK

Savigny J-C (1816) Mémoires sur les animaux sans vertèbres. Dufour, G., Paris

Sawada H, Yokosawa H, Lambert CC (2001) The biology of ascidians. Springer Japan, Tokyo

Seifert AW, Kiama SG, Seifert MG, et al (2012) Skin shedding and tissue regeneration in African spiny mice (Acomys). Nature 489:561-5. doi: 10.1038/nature11499

Slack JM (2017) Animal regeneration: ancestral character or evolutionary novelty? EMBO Rep 18:e201643795. doi: 10.15252/embr.201643795

Stolfi A, Gandhi S, Salek F, Christiaen L (2014) Tissue-specific genome editing in Ciona embryos by CRISPR/Cas9. Development 141:4115-4120. doi: 10.1242/dev.114488

Stoner DS, Rinkevich B, Weissman IL (1999) Heritable germ and somatic cell lineage competitions in chimeric colonial protochordates. Proc Natl Acad Sci USA 96:9148-9153. doi: 10.1073/pnas.96.16.9148 
Sunanaga T, Inubushi H, Kawamura K (2010) Piwi-expressing hemoblasts serve as germline stem cells during postembryonic germ cell specification in colonial ascidian, Botryllus primigenus. Dev Growth Differ 52:603-614. doi: 10.1111/j.1440-169X.2010.01196.x

Tamilselvi M, Sivakumar V (2011) Distribution of alien tunicates (Ascidians) in Tuticorin coast, India. World J Zool 6:164-172

Tiozzo S, Brown FD, De Tomaso AW (2008a) Regeneration and stem cells in ascidians. In: Stem Cells. Springer Netherlands, Dordrecht, pp 95-112

Tiozzo S, Voskoboynik A, Brown FD, De Tomaso AW (2008b) A conserved role of the VEGF pathway in angiogenesis of an ectodermally-derived vasculature. Dev Biol 315:243-255. doi: 10.1016/j.ydbio.2007.12.035

Tsonis PA (2000) Regeneration in vertebrates. Dev Biol 221:273-84. doi: 10.1006/dbio.2000.9667

Voskoboynik A, Rinkevich B, Weiss A, et al (2004) Macrophage involvement for successful degeneration of apoptotic organs in the colonial urochordate Botryllus schlosseri. J Exp Biol 207:2409-2416. doi: 10.1242/jeb.01045

Voskoboynik A, Simon-Blecher N, Soen Y, et al (2007) Striving for normality: whole body regeneration through a series of abnormal generations. FASEB J 21:1335-44. doi: 10.1096/fj.06-7337com

Voskoboynik A, Soen Y, Rinkevich Y, et al (2008) Identification of the endostyle as a stem cell niche in a colonial chordate. Cell Stem Cell 3:456-64. doi: 10.1016/j.stem.2008.07.023

Voskoboynik A, Weissman IL (2015) Botryllus schlosseri, an emerging model for the study of aging, stem cells, and mechanisms of regeneration. Invertebr Reprod Dev 59:33-38. doi: 10.1080/07924259.2014.944673

Zaniolo G, Manni L, Burighel P (1994) Ovulation and embryo-parent relationships in Botrylloides leachi (Ascidiacea, Tunicata). Invertebr Reprod Dev 25:215-225. doi: 10.1080/07924259.1994.9672388

Zondag LE, Rutherford K, Gemmell NJ, Wilson MJ (2016) Uncovering the pathways underlying whole body regeneration in a chordate model, Botrylloides leachi using de novo transcriptome analysis. BMC Genomics 17:114. doi: 10.1186/s12864-016-2435-6 